\title{
UM ESTUDO DAS REPRESENTACְ̃̃ES SOCIAIS DE ESTUDANTES DO ENSINO MÉDIO SOBRE OS INSETOS
}

\author{
Oziel Santana Neri Trindade* \\ Juvenal Cordeiro Silva Júnior* \\ Paulo Marcelo Marini Teixeira***
}

RESUMO: O objetivo do estudo foi identificar as representações sociais construídas pelos estudantes do Ensino Médio em relação aos insetos. A coleta de dados foi realizada por meio da aplicação de questionários junto a 100 estudantes de duas escolas públicas. A análise foi desenvolvida com apoio da Teoria das Representações Sociais. Os resultados indicam que os estudantes sustentam uma imagem predominantemente pejorativa em relação à grande maioria desses organismos. Tal imagem depreciativa é influenciada pelos meios de comunicação, pela escola e pelo conhecimento popular disseminado nas relações interpessoais. Ao final do trabalho, alertamos para a importância da atuação da escola na desmistificação das representações sustentadas pelos estudantes e para a construção de uma perspectiva mais ecológica na abordagem dos assuntos relacionados ao ensino de Zoologia.

Palavras-chave: Estudantes; Representações Sociais; Insetos.

\section{A STUDY OF HIGH SCHOOL STUDENTS' SOCIAL REPRESENTATIONS OF INSECTS}

ABSTRACT: The objective of this study was to identify the social representations constructed by high school students with regard to insects. Data were collected by means of the application of a questionnaire to 100 students of two public schools. The results indicate that the students hold a predominantly negative image of the great majority of these organisms. This pejorative image is influenced by the media, the school and popular knowledge spread through interpersonal relationships. At the end of the work, we point out the important role schools play in demystifying these representations held by students and in constructing a more ecological perspective in approaches to matters related to the teaching of Zoology.

Keywords: Students; Social Representations; Insects. 


\section{INTRODUĈ̣̃O}

As Representações Sociais (RS) constituem um conjunto de explicações, crenças e ideias originadas na vida diária que permitem relembrar, evocar um dado acontecimento, ser, pessoa ou objeto. Elas resultam da interação social e são comuns a um determinado grupo de indivíduos, correspondendo a uma forma de conhecimento socialmente elaborada e partilhada que contribui para a construção de uma realidade comum a um conjunto social (SÁ, 1993; ABRIC, 2001; MOSCOVICI, 2003; SOUZA e MOREIRA, 2005). As RS também são caracterizadas dentro de um tipo particular de pensamento, vinculado à prática:

As representações sociais se caracterizam precisamente por constituir modalidade de um pensamento prático. Ou seja, uma atividade mental orientada para a prática, um princípio que serve de guia para a atuação concreta sobre os homens e sobre as coisas e que pretende sistematizar os saberes pragmáticos, uma vez que, por meio da comunicação, constitui um agente da criação de um universo mental consensual (JODELET, 1984 apud SOUZA e MOREIRA, 2005, p. 95).

Por isso, Serge Moscovici - autor que lançou as bases conceituais e metodológicas para a Teoria das Representações Sociais no início da década de 60 - sublinhou que as RS “são essenciais para o entendimento da cognição social” (SOUZA e MOREIRA, 2005, p. 93). Isso significa que estudá-las e analisá-las são formas interessantes para identificar a visão de mundo que os indivíduos e/ou grupos sustentam e utilizam para atuar e tomar posição diante de situações práticas; elas são referenciais para compreendermos a dinâmica das interações sociais e evidenciar aspectos determinantes das práticas sociais (ABRIC, 2001).

A Teoria das Representações Sociais é empregada em vários campos, sobretudo nas Ciências Humanas e Sociais. Na pesquisa educacional, aparece em estudos que identificam e analisam as representações de estudantes e/ou professores sobre os mais diversos aspectos que envolvem os processos de ensino e aprendizagem (ALVES-MAZZOT'TI, 1994; SOUZA e MOREIRA, 2005).

Neste caso, dadas as nossas preocupações com o ensino de ciências e, notadamente, com o ensino-aprendizagem de conhecimentos vinculados à grande área das Ciências Biológicas, focalizamos interesse nas RS dos estudantes sobre os insetos. As representações sobre os insetos são produzidas na dinâmica cultural, isto é, elas são produtos socioculturais, e são percebidas na literatura, língua, música, artes plásticas, cinema, teatro, culinária, medicina, história representativa, religião e processos recreativos em diferentes sociedades, tanto passadas quanto contemporâneas (COSTA-NETO, 2002). Com efeito, circula na sociedade um conjunto de ideias bem arraigadas em relação aos insetos. Essas ideias são disseminadas pelos meios de comunicação, pelas demais instâncias educativas e produções culturais, contribuindo para a formação de uma imagem essencialmente pejorativa a respeito desses organismos (GRUZMAN, 2003). O próprio termo “inseto” engloba uma carga de conotação depreciativa, como registrado em muitos dicionários/ 
enciclopédias, que associam insetos a termos como "porqueiras", “imundícies" e "vermes" (ALMEIDA, 2007).

De qualquer forma, os insetos despertam considerável interesse para as pessoas. Isso acontece em função da grande diversidade de espécies que existem nessa classe e pelas relações estabelecidas entre esses animais e a espécie humana. Destacam-se, nesse sentido, a importância ecológica e econômica desses organismos, sua atuação como agentes de controle biológico, polinizadores, fornecedores de produtos alimentícios como o mel, própolis e cera, além de seu envolvimento nas atividades agropecuárias e como vetores de doenças (SILVA, ALVES e GIANNOT'TI, 2006).

Segundo Cardoso, Carvalho e Teixeira (2008), os estruturadores do currículo para a escola básica reconhecem os conteúdos de Zoologia e, dentre eles, os insetos, como assuntos importantes no âmbito do ensino de Ciências Naturais e Biologia. O conteúdo "insetos" é encontrado em praticamente todos os programas e propostas curriculares das disciplinas da área e está presente na maior parte dos livros didáticos de Ciências e Biologia voltados para a escola básica.

$\mathrm{Na}$ tentativa de romper com certos preconceitos existentes sobre os insetos, as escolas, por meio do ensino de Ciências Naturais e Biologia, particularmente nos conteúdos relativos ao estudo dos invertebrados, têm papel importante na desmistificação de informações equivocadas e distorcidas sobre esses animais. Entretanto, abordagens ultrapassadas ainda estão presentes no ensino, por meio de uma prática centrada essencialmente nas classificações sistemáticas, descrições morfofisiológicas, na memorização de termos científicos e de características de cada animal, numa apresentação fragmentada e reducionista que não especifica as relações evolutivas e ecológicas que envolvem esses organismos (AMORIM et al., 1999).

Apesar do crescente número de estudos etnoentomológicos ${ }^{1}$ em comunidades tradicionais no Brasil, existem escassos registros sobre como os estudantes de diferentes níveis de escolaridade representam os insetos, destacando-se principalmente os seguintes trabalhos: Matthews, Flage e Matthews (1997); Costa-Neto e Carvalho (2000); Gruzman (2003); Alves, (2004); Reis-Santos (2006); Souza (2007); Modro et al. (2009).

No intuito de contribuir para o preenchimento dessa lacuna, o objetivo da pesquisa foi identificar as $R S$ sustentadas pelos estudantes em relação aos insetos, comparando os resultados aqui obtidos com estudos semelhantes já realizados junto a estudantes de diferentes níveis escolares e em relação às pesquisas desenvolvidas em comunidades tradicionais. Secundariamente, analisamos possíveis influências das instâncias culturais e do conhecimento popular na formação das RS sobre os insetos identificadas junto a esses alunos.

\section{ASPECTOS METODOLÓGICOS}

Este estudo pode ser caracterizado como de natureza quali-quantitativa. O campo de coleta de dados refere-se a duas escolas públicas de Jequié/BA. Os 
critérios para a escolha dessas instituições envolveram a localização geográfica das escolas e a receptividade dos sujeitos para participação na pesquisa. A coleta de dados foi realizada em 2009 por meio de um protocolo composto de questões interrogativas e associativas, aplicado a 100 alunos de quatro turmas de $3^{\circ}$ ano do Ensino Médio. No primeiro colégio (PEB), participaram 57 sujeitos e no segundo, (EMJ) 43.

Em função da limitação de espaço, para este artigo, optamos pelo exame das informações geradas por meio da análise de conteúdo de cinco dos 11 itens incluídos no protocolo original de coleta de dados. Tal recorte foi realizado com o objetivo de valorizar as discussões relacionando a Teoria das Representações Sociais com a identificação das percepções demonstradas pelos alunos em relação aos insetos. Nesse contexto, procurou-se identificar os processos de ancoragem e o conteúdo das $R S$, além de analisar suas estruturas internas, buscando desvelar o núcleo central dessas representações (ABRIC, 2001; ALVES-MAZZOTTI, 1994; SOUZA e MOREIRA, 2005). Para desenvolver a análise dos dados, as respostas dos alunos foram categorizadas e examinadas em quadros comparativos, tabelas e gráficos.

\section{RESULTADOS E DISCUSSÃO}

A primeira questão examina as percepções dos estudantes ao observarem as figuras de diversos animais (Figura 1). Os alunos deveriam associar, para cada uma das figuras, expressões e/ou sentimentos sobre os animais ali representados.

Figura 1: llustrações utilizadas para a obtenção de expressões dos alunos sobre os animais.

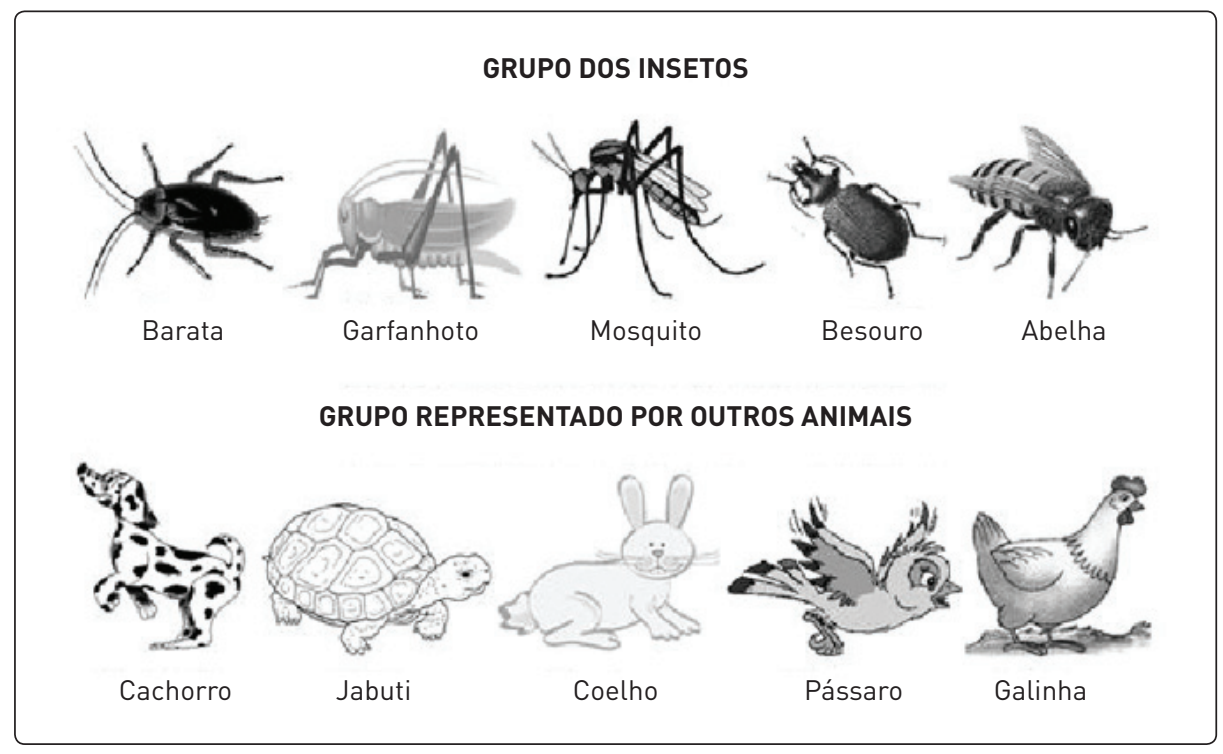


A categorização das percepções manifestadas pelos alunos em relação aos animais da Figura 1 e os resultados obtidos foram sistematizados na tabela abaixo.

Tabela 1: Categorização dos padrões de respostas dos alunos em relação aos sentimentos e/ou expressões que estes sustentam em relação aos insetos e a alguns representantes de outros grupos animais.

\begin{tabular}{|l|l|l|l|l|}
\hline \multirow{2}{*}{$\begin{array}{l}\text { Categorização das } \\
\text { Expressões }\end{array}$} & \multicolumn{2}{|l|}{ Grupo dos insetos } & \multicolumn{2}{l|}{ Grupo dos demais animais } \\
\cline { 2 - 5 } & $\mathbf{n}$ citações & $\%$ citações & n. citações & $\%$ citações \\
\hline $\begin{array}{l}\text { Expressões de natureza } \\
\text { depreciativa }\end{array}$ & 394 & 78,8 & 37 & 7,4 \\
\hline $\begin{array}{l}\text { Expressões de natureza } \\
\text { apreciativa }\end{array}$ & 62 & 12,4 & 389 & 77,8 \\
\hline Expressões ambivalentes & 32 & 6,4 & 30 & 6,0 \\
\hline Expressões sem sentido & 12 & 2,4 & 44 & 8,8 \\
\hline TOTAL & $\mathbf{5 0 0}$ & $\mathbf{1 0 0 , 0}$ & $\mathbf{5 0 0}$ & $\mathbf{1 0 0 , 0 0}$ \\
\hline
\end{tabular}

Nas duas primeiras linhas da Tabela 1 verifica-se a existência de um contraste nos padrões de expressões obtidas para os insetos em relação aos outros animais. As expressões depreciativas em relação aos insetos perfizeram 78,8\% das respostas, enquanto que para os demais animais apenas 7,4\%. Inversamente são observadas respostas de natureza apreciativa para os insetos em apenas 12,4\% dos casos, enquanto que para o grupo dos outros animais elas representaram 77,8\% das asserções explicitadas pelos estudantes. Ao mencionar expressões depreciativas em relação aos insetos, foram frequentes as citações de termos como nojo/nojento (139 citações) $)^{2}$, medo (122), pavor (29), raiva (26), doença (22), praga (20), horror/horrível (19), feio (17), pânico (13), agonia (12), chato (8) e perigo/perigoso (8). Em contrapartida, o grupo com os demais animais recebeu citações que, em geral, eram de natureza apreciativa, tais como carinho/carinhoso (56 vezes), amigo/amizade (49), fofo/fofinho/fofura (45), liberdade (43), alegria (27), amor (20) e companheiro/companhia/companheirismo (16).

Os resultados obtidos se alinham a estudo semelhante realizado por Modro et al. (2009) com professores e alunos do Ensino Médio na região de Santa Cruz do Xingu (MT). Esta pesquisa aponta que 78\% dos entrevistados concebem os insetos como organismos sem importância, atribuindo a esses animais qualidades depreciativas que desencadeiam nas pessoas reações de agressividade e aversão. A sustentação de uma perspectiva essencialmente pejorativa sobre os insetos demonstra a existência, no conjunto dos alunos, de uma visão influenciada pelo senso comum. Segundo Moscovici (2003), realidades consensuais como as $R S$ provêm do universo reificado, em que o senso comum é concebido como conhecimento produzido espontaneamente pelos membros de um grupo e fundando sobre o consenso. Esse padrão de respostas em relação aos insetos já era esperado, haja vista que outros 
estudos mostram que existe por parte das pessoas um estigma negativo em relação aos referidos animais. Isso provavelmente tomou proporções maiores ao longo do tempo, pois muitos insetos prejudicam interesses humanos quando causam danos às culturas agrícolas, alimentos armazenados, florestas, vestuários e construções; e outros atuam como vetores e transmissores de doenças que afetam o homem e os animais domésticos (HICKMAN-JR, ROBERTS e LARSON; 2004).

A segunda questão sob objeto de análise solicitou que os estudantes citassem pelo menos três palavras ou expressões que lhes vinham à mente quando eles ouviam algo sobre os insetos. Dentre outros aspectos, buscava-se, aqui, confirmar os dados obtidos na etapa anterior. Assim, a categorização das palavras ou expressões manifestadas pelos alunos em relação aos insetos foi realizada de forma mais específica, visando conhecer mais profundamente os detalhes sobre como os estudantes os concebem e, a partir disso, tentar relacionar os dados obtidos com a influência cotidiana. A categorização dos dados obtidos e sua representatividade estão descritas na Tabela 2 apresentada na sequência.

Tabela 2: Categorização dos padrões de respostas obtidos de alunos do Ensino Médio de acordo com as palavras e/ou expressões citadas pelos mesmos sobre os insetos.

\begin{tabular}{|l|l|l|}
\hline Expressões de natureza depreciativa & Citações & $\%$ \\
\hline Sentimento de nojo e repugnância & 68 & 24,3 \\
\hline Sentimento de medo, pavor, horror, aversão ou sensações correlacionadas & 61 & 21,8 \\
\hline Alusão a doenças e/ou sensações de mal-estar & 29 & 10,4 \\
\hline Situações ou sentimentos de desconforto e irritação & 19 & 5,8 \\
\hline Alusão a pragas e seu controle & 15 & 5,4 \\
\hline Adjetivação de caráter estético tais como feio, horrível, estranho & 13 & 4,6 \\
\hline Outras adjetivações depreciativas & 24 & 8,6 \\
\hline Total Parcial de Citações & $\mathbf{2 2 9}$ & $\mathbf{8 1 , 9}$ \\
\hline Expressões apreciativas ou de valorização & Citações & $\mathbf{\%}$ \\
\hline $\begin{array}{l}\text { Referências à classificação biológica, aspectos morfofisiológicos } \\
\text { e comportamentais }\end{array}$ & 16 & 5,7 \\
\hline $\begin{array}{l}\text { Alusão à natureza, equilíbrio ambiental e dos ecossistemas e a } \\
\text { preservação ambiental }\end{array}$ & 11 & 3,9 \\
\hline Sentimento de respeito, admiração e curiosidade & 7 & 2,5 \\
\hline $\begin{array}{l}\text { Alusão às cadeias alimentares e processos de decomposição e } \\
\text { controle biológico }\end{array}$ & 6 & 2,1 \\
\hline Alusão aos insetos organizados em sociedades & 1 & 0,4 \\
\hline Outras adjetivações apreciativas & 6 & 2,1 \\
\hline Total Parcial de Citações & $\mathbf{4 7}$ & $\mathbf{1 6 , 7}$ \\
\hline Palavras ou expressões sem sentido & 4 & 1,4 \\
\hline Total Parcial de Citações & $\mathbf{4}$ & $\mathbf{1 , 4}$ \\
\hline ToTAL FINAL DE CITAçõES & $\mathbf{2 8 0}$ & $\mathbf{1 0 0}$ \\
\hline
\end{tabular}


Como evidenciamos na análise da questão anterior, a categorização de palavras ou expressões de natureza depreciativa teve também maior representatividade neste segundo questionamento, perfazendo $81,9 \%$ do total de asserções obtidas contra apenas $16,7 \%$ de citações caracterizadas pela valorização da funcionalidade e importância dos insetos para os ecossistemas.

Para o conjunto de respostas depreciativas, destacam-se as seguintes categorias: i) sentimento de nojo e repugnância (24,3\%); ii); sentimento de medo, pavor, horror, aversão ou sensações correlacionadas $(21,8 \%)$; iii) alusão a doenças e/ou sensações de mal-estar (10,4\%); iv) sentimentos de desconforto e irritação $(6,8 \%)$; v); alusão às pragas e seu combate $(5,4 \%)$, que juntas totalizam $68,6 \%$ das asserções obtidas para essa questão (Tabela 2). Confirma-se novamente o predomínio de uma visão pejorativa em relação à figura dos insetos.

De acordo com Costa Neto e Pacheco (2004), entre as opções para mudar a percepção negativa que os indivíduos sustentam sobre os "insetos", estímulos sensoriais apropriados deveriam ser buscados, tais como disponibilizar espécimes nativos de cores esteticamente atraentes ou que apresentem modos de vida curiosos e interessantes.

Nas citações de natureza apreciativa ou de valorização da funcionalidade e importância dos insetos para os ecossistemas, apesar da representatividade relativamente baixa, podemos dar destaque para as seguintes categorias: i) referência à classificação biológica e aos aspectos morfofisiológicos e comportamentais dos insetos (5,7\%); ii) alusão à natureza, ao equilíbrio ambiental e dos ecossistemas e à preservação ambiental (3,9\%); iii) sentimento de respeito, admiração e curiosidade (2,5\%); e iv) alusão às cadeias alimentares, à atuação dos insetos como decompositores e no controle biológico (2,1\%) que juntas perfazem 14,2\% de um total de 16,7\%. Possivelmente essas citações surgiram como reflexo do aprendizado adquirido na escola, tornando-se significativas para o universo de compreensão dos alunos.

A percepção, identificação e classificação dos elementos faunísticos por parte de uma dada sociedade são influenciadas tanto pelo significado emotivo quanto pelas atitudes culturalmente construídas e direcionadas aos animais (SANTOS-FITA e COSTA-NETO, 2007). De forma similar, as RS se organizam e articulam-se como um saber acerca do real que se estrutura na relação do sujeito com o objeto, mediado pelas interações com os outros seres humanos e influenciado pelas diversas instâncias culturais (SHIMAMOTO, 2004).

A terceira questão sob objeto de investigação solicitava aos alunos que procurassem definir o que é um inseto. É interessante examinar a definição dos insetos em suas várias perspectivas, comparando as conceituações encontradas em dicionários/enciclopédias e aquelas manifestadas pelos estudantes. Por exemplo, é surpreendente constatar que a palavra inseto vem do latim "insecto" que significa atormentador, molestador ou ainda perseguidor, em virtude do hábito de muitos insetos perseguirem as pessoas por seus costumes hematófagos, como os mosquitos, percevejos, pulgas etc. (SOARES, 1993). O dicionário Houaiss da Língua Portuguesa especifica para o termo inseto, além das definições biológicas habituais, a associação 
do termo no sentido figurado como criaturas insignificantes, miseráveis e desprezíveis (HOUAISS, VILLAR e FRANCO, 2001).

Como se nota nessas definições, é muito intensa a presença de elementos culturais que definem a forma como um determinado termo ganha significado junto às pessoas. Essas “definições” acabam impregnando o ideário coletivo e, amiúde, vão diferir daquelas mais específicas encontradas no campo científico. Foi nessa perspectiva que arguimos os estudantes com essa questão. A categorização das respostas obtidas é apresentada na Tabela 3.

Tabela 3: Categorização dos padrões de respostas obtidos dos alunos a respeito do questionamento: Para você o que é "Inseto"?

\begin{tabular}{|l|l|l|}
\hline Categorização de acordo com o padrão de respostas & N & $\%$ \\
\hline $\begin{array}{l}\text { Insetos como animais nocivos, nojentos, desprezíveis, perturbadores e/ou } \\
\text { que geram reaç̃̃es de pânico e/ou medo }\end{array}$ & 52 & 28,6 \\
\hline $\begin{array}{l}\text { Insetos como transmissores de doenças ou agentes que atuam em } \\
\text { oposição ao estado de saúde e bem-estar do ser humano }\end{array}$ & 29 & 15,9 \\
\hline Insetos como organismos que possuem funcionalidade ecológica & 27 & 14,8 \\
\hline Insetos dentro de uma abordagem conceitual ou taxonômica & 25 & 13,7 \\
\hline Referência a aspectos morfofisiológicos dos insetos & 16 & 8,8 \\
\hline Insetos como pragas na agropecuária & 15 & 8,2 \\
\hline Insetos concebidos por meio de uma valorização estética negativa & 6 & 3,3 \\
\hline Concepção de natureza apreciativa sobre os insetos & 5 & 2,7 \\
\hline Insetos confundidos com representantes de outros grupos animais & 3 & 1,6 \\
\hline Outras opiniões, ideias difusas e sem sentido & 4 & 2,2 \\
\hline Totais & $\mathbf{1 8 2}$ & $\mathbf{1 0 0 , 0 0}$ \\
\hline
\end{tabular}

Os insetos concebidos como animais nocivos, nojentos, desprezíveis, pragas, que geram reações de pânico e/ou medo e associações com a transmissão de doenças foram os parâmetros mais expressivos nesta questão $(56 \%)$, em sintonia com o trabalho de Modro et al. (2009), ao demonstrarem que estudantes e professores da escola básica também manifestam representações de aversão, nojo, incômodo e medo, fazendo referência à atuação dos insetos como animais perigosos e causadores de danos à saúde humana. Ainda segundo os referidos autores, provavelmente tais reações aversivas são construídas, pois a maioria das pessoas está mais informada sobre os danos que os insetos causam do que sobre potenciais benefícios que eles trazem. Além disso, a maneira como o indivíduo percebe, identifica, categoriza e classifica o mundo natural influencia o modo como ele pensa, age e expressa emoções com relação aos animais (POSEY, 1987). 
Costa-Neto e Carvalho (2000) realizaram trabalho semelhante com 533 alunos de diversos cursos de graduação, encontrando resultados relativamente diferentes. No referido trabalho, quando questionados sobre "Para você, o que é um inseto?' o caráter conceitual foi o mais expressivo, enquanto que em nosso estudo tivemos apenas 13,7\% para esse padrão de resposta. Similarmente, em relação ao caráter ecológico, os autores constatam que foi a segunda abordagem mais frequente, enquanto que em nosso trabalho representou apenas 14,8\%. É possível supor que a diferença evidenciada nos resultados de ambos os trabalhos refere-se à relativa disparidade de grau de instrução entre os participantes. Considerando que Costa-Neto e Carvalho (2000) trabalharam com alunos de graduação, sendo que o curso com maior número de participantes foi o de Ciências Biológicas, é inegável que esses alunos teriam maior facilidade para desenvolver abordagens de caráter conceitual e ecológico do que os alunos que foram investigados em nosso estudo.

Alguns dos participantes da pesquisa assinalaram os insetos como representantes de outros grupos animais:

\section{"Inseto é um bicho muito perigoso, alguns insetos leva (sic) até a morte. Princi- palmente cobra, escorpiāo e outros que leva (sic) até ficar paralítico." "Inseto pra mim é mosca, barata, lagarto e gongo."}

A hipótese da ambivalência entomoprojetiva, segundo a qual os seres humanos tendem a atribuir características dos insetos a animais que não pertencem a esse grupo, explica essas afirmações. Nas frases evidenciadas, cobras (réptil), escorpiões (aracnídeo), lagartos (réptil) e gongos (diplopoda) são associados aos insetos. Isso acontece porque os seres humanos respondem à diversidade faunística de seu ambiente agrupando os animais pelas semelhanças e separando-os pelas diferenças. Os processos de categorização são influenciados culturalmente e organizados em padrões lógicos (estruturas taxonômicas) distintos para cada sociedade (COSTA-NETO, 2000). A categoria “inseto”, na percepção das pessoas é, portanto, bastante fluida, abrangendo vários táxons além da classe insecta, como mamíferos, aves, anfíbios, répteis e também outros artrópodes.

No quarto item, os estudantes foram estimulados a construir uma frase que integrasse as seguintes palavras: insetos, natureza e homem. A análise qualitativa das frases dos alunos permitiu sua classificação conforme as seguintes categorias: a) Neutras: enfocam tanto aspectos negativos quanto positivos da relação insetos-homem-natureza; b) Depreciativas: enfocam apenas aspectos negativos da relação insetos-homem-natureza; c) Apreciativas: enfocam apenas aspectos positivos da relação insetos-homem-natureza.

Surpreendentemente, 69\% dos alunos construíram frases enquadradas como neutras, ou seja, elas contemplam, simultaneamente, aspectos positivos e negativos a respeito dos insetos. Fica evidente que quando os alunos encaram a figura dos insetos dentro de um contexto relacional, envolvendo também o homem e a natureza, as opiniões de caráter pejorativo predominantes na análise das questões 
anteriores se diluem, cedendo espaço para representações que incorporam simultaneamente aspectos pejorativos e apreciativos sobre os insetos. Vejamos abaixo algumas das frases que ilustram essa situação:

\section{"A natureza é constituida pelos homens e insetos que podem prejudicar a natureza, como também contribuir para o seu crescimento trazendo benefícios." "Mesmo que o homem não goste de conviver com os insetos, eles são indispensáveis para a natureza." \\ "O inseto causa prejuízo ao homem, mas na natureza tem um papel importante."}

Nesse sentido, sugerimos a necessidade de estabelecer, no ensino de Ciências/ Biologia, um enfoque mais relacional, de forma que seja possível evitar o estudo dos insetos realizado de forma isolada, fragmentada e memorística. Gruzman (2003) ressalta a importância de se pensar numa atividade educativa que busque alternativas para representar os insetos tentando significá-los em seu próprio ambiente, e não numa representação antropocêntrica em que a imagem dos insetos estará ligada a conceitos exteriores a eles e a preconceitos históricos consolidados que desvalorizam esses animais. Acrescentamos, aqui, a necessidade de relacionar o estudo dos insetos a suas relações ecológicas, aproveitando para incentivar a realização de trabalhos semelhantes ao realizado por Vital et al. (2004) que podem demonstrar o grande potencial do uso de insetos como recurso didático em experimentos de ecologia de populações.

Outro fator surpreendente verificado nas frases dos alunos refere-se à construção de frases caracterizadas por uma visão crítica do papel desempenhado pelo homem como depredador da natureza, conforme evidenciado nos seguintes exemplos:

\section{"A natureza é a casa dos insetos e os homens invadem." "O inseto vive na natureza e o homem destrói os insetos e a natureza." "Os insetos agem de forma estratégica na natureza, porém o homem com os seus ideais procuram de alguma forma destruir o habitat dos insetos."}

Fica evidente que os estudantes percebem a ação degradadora realizada pela espécie humana como um fator de intervenção negativa na natureza e, consequentemente, para os insetos. Essas noções devem ser estimuladas de forma que o estudante possa relacionar aspectos positivos e negativos dos insetos, instigando sua formação como uma "nova pessoa" com um conhecimento crítico, uma atitude questionadora, compreensiva, flexível e capaz de construir novos significados a partir das experiências cotidianas (MODRO et al., 2009).

Um último aspecto a ser mencionado se refere a como os estudantes obtiveram informações a respeito dos insetos. Notou-se que a mídia (televisão, rádio, internet, revistas e jornais) atua de forma significativa na disseminação de informações sobre os insetos, com a televisão se configurando como o principal 
instrumento de transmissão dessas informações, sendo citada por 86\% dos participantes. Segundo Gruzman (2003), os filmes de ficção, documentários, músicas, reportagens, vídeos educativos e anúncios publicitários podem contribuir para a construção de representações negativas sobre os insetos.

Há várias explicações para a importância dos insetos na cultura humana, mas seu significado, frequentemente, repousa em um valor simbólico. Este valor é explorado pela arte da publicidade, que faz uso da imagem dos insetos veiculando mensagens implícitas ou explícitas sobre produtos e serviços, capitalizando atitudes tanto negativas quanto positivas envolvendo a figura desses animais (COSTA-NETO, 2000). Marques e Andrade (1998) denominam esse fenômeno de "semiótica publicitária zoofílica”, que concebe a existência de uma ligação inata entre os seres humanos e os animais.

A escola $(83 \%)$ e os livros didáticos $(79 \%)$ também exercem influência nas representações dos alunos sobre os insetos. Sobre a abordagem do conteúdo insetos na escola, Gruzman (2003) assinala que os insetos são quase sempre representados de forma fragmentada e isolada do seu ambiente; os livros, as imagens e os textos não dão conta de mostrar os insetos em sua integralidade. Ao contrário, mostram esse grupo apenas a partir de uma perspectiva de descrição morfológica e taxonômica, isto é, focalizam as características corpóreas dos insetos e sua classificação dentro do grupo maior dos artrópodes, sem procurar compreendê-los numa perspectiva ecológica. $\mathrm{O}$ autor reforça ainda que a partir do momento em que se quebra esse vínculo entre os insetos e o ambiente, os insetos passam a ter um significado reducionista e suscetível a interpretações meramente ancoradas na perspectiva antropocêntrica.

Os participantes da pesquisa também citaram ter obtido informações sobre os insetos a partir do contato direto com as pessoas, entre as quais pais, amigos, colegas, vizinhos, professores, agentes de saúde, biólogos e outros profissionais. Essa troca direta de informações no cotidiano, somadas às experiências adquiridas por meio de uma gama de informações veiculadas pela mídia, faz com que conceitos, proposições, explicações e ideias sobre os insetos sejam construídas e interpretadas de diferentes formas, constituindo, assim, o cerne da elaboração das Representações Sociais sobre os insetos.

\section{CONSIDERACְÕES FINAIS}

Os resultados revelam aspectos socioculturais intimamente relacionados à visão que os estudantes estruturam sobre os insetos, e que muitas das representações construídas pelos estudantes são fortemente influenciadas pelo conhecimento adquirido por meio das interações e práticas sociais cotidianas.

A veiculação contínua de informações pela mídia, a aprendizagem obtida nas escolas e o contato com o conhecimento popular fazem parte da complexa teia de práticas sociais que ajudam a construir as RS sobre os insetos. A forma 
como esse conhecimento é elaborado e compartilhado socialmente induz os estudantes a valorizarem aspectos negativos sobre os insetos. Porém, quando os estudantes são estimulados a pensar relacionalmente, parece que essa tendência negativa se dilui um pouco.

Os resultados encontrados neste trabalho se alinham a estudos semelhantes realizados junto a estudantes de diferentes níveis de instrução e com pessoas de comunidades tradicionais, apontando que os estudantes, assim como acontece com boa parte das pessoas, sustentam representações diversas associadas à repugnância e aversão em relação aos insetos. Eles tendem a associar de forma acentuada a figura desses animais a problemas como a disseminação de doenças e a atuação como pragas urbanas e agrícolas, num viés de caráter claramente antropocêntrico.

Foi detectado que a ideia de nocividade parece atuar como o núcleo central das $R S$ sobre os insetos. Ela é o elemento que apresenta maior resistência à mudança, constituindo o componente que induz a predominância do significado pejorativo verificado para os insetos. Shimamoto (2004) esclarece que dentro das RS o núcleo central é o elemento que vai apresentar maior resistência a mudanças, e é este que lhe confere perenidade em contextos móveis e evolutivos. Neste caso, a nocividade atribuída aos insetos torna-se um elemento central, pois mantém um laço privilegiado com o objeto da representação. Entretanto, ressalta-se que as RS não podem ser reduzidas a apenas opiniōes de ou imagens de, mas constituem teorias coletivas sobre o real, reinterpretadas pelos sujeitos; sistemas dotados de uma lógica e uma linguagem particulares, uma estrutura de implicações baseada em valores e conceitos, destinada à interpretação e elaboração do real (SHIMAMOTO, 2004).

Com base nos dados obtidos na investigação e considerando que as $R S$ são utilizadas como "verdadeiros" sistemas de interpretação do mundo, orientando nossas condutas e ações, salientamos a importância da atuação da escola na desmistificação das concepções equivocadas sustentadas pelos estudantes em relação aos insetos. É preciso pensar em aulas sobre o assunto que problematizem as perspectivas antropocêntricas e utilitaristas e, além disso, levem em conta as dimensões ecológicas e evolutivas sobre os insetos: é preciso deslocar a abordagem dos assuntos relacionados ao estudo dos seres vivos de uma visão estritamente "pautada no humano" para uma perspectiva que leve em conta "as adaptações dos seres vivos aos seus ambientes, bem como as suas relações com os demais seres vivos sem uma leitura antropocêntrica de suas ações” (SANTOS, 2000, p. 17). Além disso, considerando que o conhecimento prévio é uma variável importante na aprendizagem de novos conhecimentos, fica evidente a necessidade de que, cada vez mais, educadores e pesquisadores explorem as RS que os alunos trazem para a sala de aula.

\section{NOTAS}

\footnotetext{
${ }^{1}$ A etnoentomologia é um campo de estudos sobre as interações que as sociedades humanas mantêm com os insetos, isto é, é o campo de pesquisa que estuda como os insetos são percebidos, classificados, conhecidos e utilizados pelas populações humanas (POSEY, 1987; BERLIN, 1992).
} 
Um estudo das representações sociais de estudantes do ensino médio sobre os insetos

${ }^{2}$ Os números entre parênteses representam a quantidade de citações que cada termo recebeu por parte do conjunto de estudantes envolvidos na pesquisa.

\section{REFERÊNCIAS}

ABRIC, J. C. Prácticas sociales y representaciones. México: Ediciones Coyoacán, 2001.

ALMEIDA, A. V. Os insetos brasileiros descritos pelo naturalista Georg Marcgrave. Episteme, Porto Alegre, n. 25, p. 7, jan/jun. 2007.

ALVES, N. G. S. O sentir, o pensar e o saber sobre insetos no ensino médio e superior no município de Jequié, $B A$. Monografia (Licenciatura em Ciências Biológicas) - Departamento de Ciências Biológicas, Universidade Estadual do Sudoeste da Bahia, Jequié, 2004.

ALVES-MAZZOTTI, A. J. Representações sociais: aspectos teóricos e aplicações à educação. Em Aberto, Brasília, ano 14, n. 61, p. 60-78, jan./mar. 1994.

AMORIM, D. S. et al. Diversidade biológica e evolução: uma nova concepção para o ensino. In: BARBIERI, M. R., SICCA, M. A. L.; CARVALHO, C. P. (Orgs.). Aulas de Ciências. Ribeirão Preto: Holos, 1999.

BERLIN, N. Ethnobiological classification: principles of categorization of plants and animals in traditional societies. New Jersey: Princeton University Press, 1992.

CARDOSO, J. S.; CARVALHO, K. S.; TEIXEIRA P. M. M. Um estudo sobre a abordagem da Classe Insecta nos livros didáticos de Ciências. Sitientibus, Feira da Santana, v. 8, n. 1, p. 80-88, Mar. 2008.

COSTA NETO, E. M. Manual de etnoentomología. Zaragoza: Manuales \& Tesis SEA, 2002.

. Introdução à etnoentomologia: considerações metodológicas e estudo de casos. Feira de Santana/ BA: 2000 .

.; CARVALHO, P. D. Percepção dos insetos pelos graduandos da Universidade Estadual de

Feira de Santana, Bahia, Brasil. Acta Scientiarum, Maringá, v. 22, n.2, p. 423-428, 2000.

.; PACHECO, J. M. A construção do domínio etnozoológico "inseto" pelos moradores do povoado de Pedra Branca, Santa Terezinha, Estado da Bahia. Acta Scientiarum Biological Science, Maringá, v. 26, n. 1, p. 81-90, 2004.

GRUZMAN, E. Representacõoes dos insetos através da imagem: uma investigação teórico-prática para a realização de um vídeo educativo em ecoentomologia. Dissertação (Mestrado) - NUTES, Universidade Federal do Rio de Janeiro, Rio de Janeiro, 2003.

HICKMAN-JR; C. P.; ROBERTS, L. S.; LARSON, A. Princípios Integrados de Zoologia. Rio de Janeiro: Guanabara Koogan, 2004.

HOUAISS, A.; VILLAR, M. S.; FRANCO, F. M. M. Dicionário Honaiss da Lingua Portuguesa. Rio de Janeiro: Objetiva, 2001.

MARQUES, J. G. W.; ANDRADE, C. T. S. Semiótica Publicitária Zoofílica. 1- Peixe é bom para “vender o peixe". In: Simpósio Brasileiro de Etnobiologia e Etnoecologia, 2, 1998, São Carlos. Resumos... São Carlos: UFSCar, 1998, p.89.

MATTHEWS, R.W.; FLAGE, L. R.; MATTHEWS, J. R. Insects as teaching tools in primary and secundary education. Annual Review of Entomology, v. 42, p. 269-289, 1997.

MODRO, A. F. H. et al. Percepção entomológica por docentes e discentes do município de Santa Cruz do Xingu, MT, Brasil. Biotemas, Florianópolis, v. 22, n. 2, p. 153-159, 2009.

MOSCOVICI, S. Representações Sociais: investigações em Psicologia Social. Petrópolis/ RJ: Vozes, 2003.

POSEY, D. A. Temas e inquirições em etnoentomologia: algumas sugestões quanto à geração de hipóteses. Boletim do Museu Paraense Emílio Goeldi, Belém, v. 3, n. 2, p. 99-134, 1987.

REIS-SANTOS, D. Aprendizagem lúdica sobre insetos no ensino fundamental. Monografia (Licenciatura em Ciências Biológicas) - Departamento de Ciências Biológicas, Universidade Estadual do Sudoeste da Bahia, Jequié, 2006.

SÁ, C. P. Representações sociais: o conceito e o estado atual da teoria. In: SPINK, M. J. (Org.). O conhecimento no cotidiano. São Paulo: Brasiliense, 1993, p. 19-45. 
SANTOS, L. H. Tem alguma utilidade estudar a utilidade dos seres vivos? In: . (Org.). Biologia dentro e fora da escola. Porto Alegre: Ed. Mediação, 2000, p. 13-24.

SANTOS-FITA, D.; COSTA-NETO, E. M. As interações entre os seres humanos e animais: a contribuição da etnozoologia. Biotemas, Florianópolis, v. 20, n. 4, p. 99-110, 2007.

SHIMAMOTO, D. F. As Representacões Sociais dos professores sobre corpo bumano e suas repercussões no ensino de ciências naturais. Tese (Doutorado) - Universidade Federal de São Carlos, São Carlos, 2004.

SILVA, E. R. L.; ALVES, L. F. A.; GIANNOTTI, S. M. Análise do conteúdo de Artrópodes em livros didáticos de Biologia do Ensino Médio e o perfil do professor: estudo de caso. Revista Varia Scientia, Cascavel/PR, v. 6, n. 11, p. 83-98, 2006.

SOARES, J. L. Dicionário etimológico e circunstanciado de Biologia. São Paulo: Scipione, 1993.

SOUSA, C. M. S. G.; MOREIRA, M. A. Representações Sociais. In: MOREIRA, M. A. (Org.). Representações mentais, modelos mentais e representações sociais. Porto Alegre: UFRGS/IF, 2005, p. 91-128.

SOUZA, F. B. Conhecimento de crianças de séries iniciais sobre os insetos: contribuições da etnoentomologia para o ensino de Zoologia. Monografia (Licenciatura em Ciências Biológicas) - Departamento de Ciências Biológicas, Universidade Estadual do Sudoeste da Bahia, Jequié, 2007.

VITAL, M. V. C. et al. Insetos em experimentos de ecologia de populações: um exemplo de abordagem didática. Acta Scientiarum, Maringá, v. 26, n.3, p. 287-290, 2004.

Data do Recebimento: 21/10/2010

Data de Aprovação: 23/12/2011

Data da Versão Final: 03/05/2012 